\title{
Analysis of the Characteristics and Legislation of Life-long Education System in Korea based on Social Education
}

\author{
Shu Jin ${ }^{1}$, Guangda Xu ${ }^{2}$ \\ ${ }^{1}$ Foreign Languages College, Beihu University, Jilin, Jilin, 132013 \\ ${ }^{2}$ Orthopedics department, People’ Hospital of Jilin City, Jilin, Jilin, 132013
}

Keywords: Characteristics and Legislation Research, Korea, Life-long Education System.

\begin{abstract}
In today's world, with the rapid development of economy and the popularization of the network, the rapid growth of information and knowledge, the rapid development of science and technology, the improvement of national quality for the national economic development and social progress more and more obvious, which requires the way through lifelong education Improve the quality of the people. Therefore, countries around the world attach great importance to the development of lifelong education. July 29, 2010, Chinese "National Medium and Long-term Education Reform and Development Plan (2010-2020)" put the concept of lifelong education as an important guiding ideology, put forward "to build a flexible and open lifelong education system", " Learning 'overpass' "," to 2020 to create a study of everyone, everywhere can learn, always learn the learning society, "the development of strategic objectives. However, due to the late life education theory and practice in China started late, the domestic research results in this field is small and lack of practical, therefore, learn from other countries, the excellent experience of lifelong education management for our country's life-long education practice has important theory and Practical significance.
\end{abstract}

\section{Introduction}

The history of modern life-long education is not long, and the education of all countries is in the process of continuous reform and adjustment. Scholars' understanding and expression of lifelong education are different. There are differences in the description of their characteristics, but the general view all believe that lifelong education has the following characteristics: life. This is the greatest feature of lifelong education. It breaks through the framework of formal schools, regards education as a continuous process of learning in a lifetime of life, the sum of the various cultures that people receive in their lives, and the unity of the entire educational process from pre-school to old age The Both formal education and non-formal education. It covers the various stages and forms of the educational system. It refers to those who accept lifelong education, including all the people, both men and women, poor, rich and poor, race, gender. United Nations Educational, Scientific and Cultural Organization (UNESCO) Burger Education researcher Dabe suggests that lifelong education is democratized and that education against the so-called elite is an equal opportunity for the general public to have access to education. In fact, every person in today's society must learn to survive, and to learn to survive can not be separated from life-long education, because survival and development is the mainstream of the times, will survive to learn, it is modern society to everyone new topic. It breaks the restrictions on people's education, giving individuals the possibility of flexible handling of mobile mobility, so that the cause of public welfare, convenience to the development of unprecedented height. Lifelong education includes both family education, school education, and social education. It can be said that it includes all the stages of the people, all the time, all places, all occasions and all aspects of education. Lifelong education has expanded the study of heaven and earth, for the entire cause of education into a new vitality. Performance in any need to learn people, anytime, anywhere to accept any form of education. The time, place, content, 
and manner of learning are determined by the individual. People can choose according to their own characteristics and needs the most suitable for their own learning.

\section{Analysis on the Management Mechanism of Life-long Education in Korea}

With the rapid development of domestic lifelong education in Korea, the Korean government carried out a large-scale revision of the "Lifelong Education Law" in 2007, and the revised version became the text of Chapter 8 and Chapter 1, Article 46 Article. The second chapter is the basic plan for the implementation of lifelong education, and clearly stipulates that the central and local governments should give lifelong education to the institutions that provide for life-long education. Financial and financial support; the third chapter is the lifelong education promotion institute, standardize the central, the city and the city, the county district to set up the promotion unit, establishes the study account; The fourth chapter is the lifelong education teacher, The fifth chapter is the lifelong education facilities, standardize the lifelong learning hall, school, the media in the lifelong education on the work and content; the sixth chapter for the literacy education, standardize the implementation of lower than junior high school education adult education The National and local governments to handle literacy education, so that people out of school to reach the level of junior high school education. Chapter 7 is the management of the results of the study and the establishment of life-long learning, norms in the lifelong education-related units to attend the course to give a formal credit or degree of certification, the school should be given the same degree of education, And in the community to be formally recognized; Chapter VIII to supplement the rules, regulate the administrative sanctions, hearings held, prohibit the use of lifelong learning and revitalization, learning, committees, councils and other similar names and penalties; For the appendix, for the implementation of the first eight rules.

South Korea's "Lifelong Education Law" in its general principles that is clearly put forward the purpose of legislation and the concept of life-long education philosophy of the core ideas to promote the development of lifelong education is an important principle, which in the world of relevant laws is rare, but also worthy of its life education legislation for reference. Professor Ban Fuxian of Korea pointed out that the purpose of formulating the Lifelong Education Act is to establish an open educational society, to learn society for life and to create a learning atmosphere to guarantee national learning rights and options. To improve the treatment of lifelong education courses and to meet the needs of lifelong learning, To the education-based society; into a practical ability-based society, to expand adult education opportunities and improve the quality of higher education, so that national and local self-government education has been strengthened, training knowledge human development industry and education Training industry ". (1) The core idea of the law includes the principle of equal lifelong learning, freedom and volunteer participation in lifelong learning for every citizen. Lifelong education shall not be used as a means of political and personal prejudice. , Life advocacy should respect the needs and practicality of learners, etc. These ideas have become important principles and basis for promoting the development of lifelong education in the country.

In the newly revised Korea Lifelong Education Act, the original law "set up a Lifelong Education Council in the Central Committee for the Establishment of Lifelong Education Promotion Committee, Local Market, City and County" is only a committee of consultative nature. The

"National Lifelong Education Promotion Institute" and the "Lifelong Education Promotion Institute" at the municipal level and the "Lifelong Learning Center" at the municipal level are the government organizations dedicated to the implementation of lifelong education policies. The main task is to plan for the promotion of lifelong education, support, legal formulation, learning account management, personnel training and training, information system management, contact coordination, which for the Korean lifelong education to promote the system to establish a complete structure, and "lifelong education Law "for all levels of government should have clear provisions of the matter, not only from the policy to give a macro guide, but also in practice to give specific guidance; to implement ineffective and false means to develop sanctions, strong and effective 
management measures for the development of lifelong education in South Korea has a great role in promoting.

\section{Korea Life Education Development Management Mechanism of Operation Legislation}

Today's world is a rapid development of the economy, technology with each passing day, the rapid expansion of knowledge of society, the traditional learning philosophy has been unable to adapt to the changing new situation. Since the development of lifelong education in Korea, since the idea of modern lifelong education spread to South Korea, the South Korean government has always attached great importance to this idea, and is committed to encouraging all citizens to participate in lifelong learning, both in the 1970s, President Park Chung-hee initiated "New Village Movement", or Kim Dae-jung, through the lifelong education legislation to promote the economy out of the crisis, or the recent adoption of the "national subsidy overseas training and employment project" to solve the employment, have shown that the Korean government has been lifelong education as a rapid economic development, And continuously enhance the overall competitiveness of the country's important backing, and economic development and in turn promote the development of lifelong education. This benign mechanism of mutual promotion makes the concept of lifelong education easier for national acceptance. It is precisely because the national identity of the concept of lifelong education makes South Korea in a few decades to quickly develop into a more perfect life-long education system, lifelong education development in the world at the advanced level of the country.

With the continuous development of society, the scope and influence of lifelong education is expanding day by day, it is very important to standardize and guarantee the development of lifelong education through legislation. South Korea's practice in lifelong education legislation is worth learning and learning from the introduction of lifelong education began, the South Korean government has been trying to pass the law to lifelong education to the country, from the "new constitution" in the concept of lifelong education to "society Education Promotion Law "in the express provision, and then to the" Lifelong Education Law "and the implementation of the regulations specifically formulated, South Korea only 20 years or so to develop a more perfect on life-long education laws, become the world's first development of lifelong education one of the countries that specializes in law shows the strong determination of the Korean government to develop lifelong education. On the other hand, South Korea's "Lifelong Education Law" and its implementation details are comprehensive, including all aspects of the implementation of lifelong education in the country, and the provisions of the duties clear, strong measures, a good guarantee of the construction of lifelong education system and life the smooth implementation of educational policy is a strong guarantee for the development of lifelong education in Korea.

The implementation of the law of lifelong education, the implementation of policies need to have a special administrative agencies to monitor and implement, but also the need for a variety of civil institutions and facilities as a lifelong education development platform. The Korea Life Education Act clearly stipulates the life-long education management institutions from the central to the localities, which are always concerned with the information and dynamics of lifelong education development, formulate policies and systems related to lifelong education, develop lifelong education-related projects, run lifelong learning account, credit bank, degree self-study system and other life-long education, for the development of lifelong education is of great significance. In addition, there are a large number of civil lifelong educational institutions and facilities in Korea, such as the University of Lifelong Education, civic associations, network distance education institutions, major enterprises of the internal staff training institutions and so on for the development of lifelong education provides a good Platform, so that South Korean nationals can enjoy life and education opportunities anytime, anywhere, is worth learning and learn from China.

\section{Conclusion}

After decades of development, life education has become the most important educational 
philosophy in the world today. It has become more and more important for the improvement of national quality, economic development and social progress. More and more countries in the world have paid more attention to the development of lifelong education. This paper analyzes the development course, legislation situation, policy system, promotion mechanism, management institution and characteristic project of lifelong education in Korea, summarizes the advanced practices and lessons learned from the development of lifelong education in Korea, and constructs the lifelong education system, the establishment of a learning society put forward their own suggestions. The author believes that the Korean government has always attached importance to the development of lifelong education, in the lifelong education legislation, lifelong learning achievement certification system, learning city construction and overseas training and employment and other characteristics of the project has been more mature, advanced and innovative. The current China should vigorously develop lifelong education, the establishment of lifelong education system, in many aspects can learn from South Korea.

\section{Acknowledgements}

Jilin Philosophy and Social Science Planning Fund Project: "South Korea's small-scale school merger policy on Chinese rural primary school evacuation and school revelation research" Topic: 2014B71

Jilin Social Science and Technology Joint Project: "Korean University Employment Guidance Research and its reference" Project ID: Province Union1618-2

Jilin Social Science and Technology Joint Project: "South Korea abandoned primary school building re-use of rural primary schools in China and the school point of inspiration" Topic: Province Union 1421-1

\section{References}

[1] Wang Taotao. Study on the learning account system of lifelong education system in Korea [J]. Journal of continuing education 2011 (11)

[2] Wu Chunyu. Study on the development characteristics of lifelong education in Korea [J]. Coal Higher Education. 2010 (03)

[3] Yu Jing. South Korea lifelong education management institutions status and enlightenment[J]. World Education Information. 2010 (02)

[4] Luo Jihe. The legislative protection of lifelong education in China - the enlightenment of foreign lifelong education legislation[J]. Adult Education. 2009 (07)

[5] Qi Yonghua. Korean life-long education development and practical operation[J]. Adult Education. 2009 (03)

[6] Lei Liping. South Korea's vocational and technical education development and reform of Chinese enlightenment[J]. Northeast Asia Forum. 2008 (02)

[7] Xia Pengxiang. Japan's life-long education policy implementation status analysis[J]. Journal of Japan Journal (2008) 